\title{
Disciplina de Língua Portuguesa - importância curricular no curso de Odontologia
}

\section{O ensino de Lingua Portuguesa nos cursos de Odontologia visa suprir as deficiências da formação dos alunos e desenvolver habilidades de leitura e interpretação de textos científicos.}

\author{
Luciana Corrêa*, Sandra Pacca** \\ * Professora Titular da Disciplina de Língua Portuguesa do Curso \\ de Odontologia da Universidade Braz Cubas. \\ ** Professora Associada da Disciplina de Histologia Básica do Curso \\ de Odontologia da Universidade Braz Cubas.
}

\section{RESUMO}

A disciplina de Língua Portuguesa faz parte do currículo obrigatório para os alunos ingressantes na Universidade Braz Cubas (UBC). O programa dessa disciplina é universal para todos os cursos da UBC e tem como foco principal o desenvolvimento das habilidades do aluno no tocante à leitura e escrita de textos científicos. Para tal, são enfatizados principalmente os princípios de coesão e coerência textuais, bem como tópicos gramaticais direcionados à ortografia e à sintaxe. Em fevereiro de 2002, o programa da disciplina de Língua Portuguesa foi modificado para o curso de Odontologia, tornando essa disciplina mais específica às necessidades dos alunos da área de saúde voltados à ciência odontológica. Para promover essa modificação, foi realizado um diagnóstico prévio da situação lingüística dos estudantes ingressantes. O presente trabalho focaliza os princípios metodológicos que nortearam esse diagnóstico, apresenta metodicamente as falhas na produção textual dos alunos, bem como discute as modificações principais criadas na disciplina e seus efeitos no currículo de Odontologia da UBC.

\section{DESCRITORES}

Ensino, tendências. Educação em Odontologia. Currículo.

$\mathbf{U}$ $\mathrm{m}$ docente de curso superior hoje, principalmente de uma instituição privada, se depara com dois problemas cruciais, dentre tantos outros: um aluno com pouca ou nenhuma base do colegial e um currículo que não prevê essa deficiência (SOUZA, 2003). A despeito das dificuldades de aprendizado do aluno, esse docente tem o compromisso, antes de mais nada, de cumprir o seu cronograma, ministrando pelo menos $75 \%$ do seu conteúdo programático constante na ementa de sua disciplina. O professor do curso superior diagnostica facilmente que o aluno é deficiente (FERNANDEZ, 1993) - ainda que superficialmente faça esse diagnóstico -, porém, em nome do bom andamento do curso, sente-se impotente diante do fato e preocupa-se em transmitir as informações de seu programa.

Várias instituições de ensino superior tentam reverter essa situação inserindo nos currículos de seus cursos disciplinas complementares que visam suprir, principalmente no primeiro semestre, as deficiências de base do aluno, bem como atenuar o contraste que ocorre entre o ambiente do ensino médio e do ensino superior. Particularmente nos cursos de Odontologia, muitas universidades incluem disciplinas como Língua Portuguesa, Língua Inglesa e Informática no primeiro semestre, com o intuito de fornecer algumas ferramentas ao aluno para minimizar suas deficiências de aprendizado.

No tocante à Língua Portuguesa, os cursos de Odontologia que oferecem essa disciplina em seus currículos apresentam, em geral, uma ementa voltada para desenvolver habilidades de leitura e interpretação de textos científicos. Princípios de comunicação verbal (oral e escrita) são também abordados, 
com o intuito de evidenciar ao aluno os princípios básicos que regem um texto.

Na Universidade Braz Cubas (UBC), de Mogi das Cruzes, a disciplina de Língua Portuguesa é de caráter obrigatório e é ministrada nos primeiros semestres de todos os cursos da Universidade em todas as áreas do conhecimento.

Nos últimos anos, os graduandos do curso de Odontologia da UBC estavam demonstrando insatisfações quanto à abordagem da Língua Portuguesa considerando o contexto do currículo odontológico. Em muitos momentos, a importância da disciplina era questionada, havendo um subaproveitamento dos alunos. Foram realizadas, então, modificações na ementa da disciplina, a qual foi direcionada mais para o contexto odontológico. Para tal, foi realizado um prévio diagnóstico do nível de produção textual dos alunos, com o intuito de criar um perfil desse estudante quanto à sua situação lingüística.

O presente trabalho focaliza os princípios metodológicos que nortearam esse diagnóstico, apresenta metodicamente as falhas na produção textual dos alunos, bem como discute as modificações inseridas na ementa da disciplina com base na realidade do aluno de Odontologia ingressante na UBC. São tecidas também reflexões acerca do papel da disciplina de Língua Portuguesa nos currículos de Odontologia.

\section{MATERIAL E MÉTODOS}

Durante o primeiro semestre de 2002, foram realizadas modificações na disciplina de Língua Portuguesa do curso de Odontologia, tendo como público-alvo 50 alunos de graduação, oriundos principalmente dos estados de São Paulo, Minas Gerais, Rio de Janeiro e Pará. Os alunos tinham em média 21 anos de idade (mínima de 18 e máxima de 24 anos), havendo cerca de $15 \%$ de alunos com história de ensino fundamental e médio em escolas públicas.

As modificações realizadas praticamente não envolveram as alterações dos objetivos da disciplina, mas sim o desenvolvimento de novas estratégias de abordagem. Priorizou-se a execução de exercícios durante as aulas, os quais foram baseados nas disciplinas cursadas no primeiro semestre do curso de Odontologia: Histologia Básica, Anatomia Básica, Bioquímica, Odontologia Social e Biologia.

Esses exercícios continham tópicos ou temas já vistos pelo aluno em suas aulas e foram construídos com a participação direta do docente responsável pelo assunto. Foram selecionados, assim, trechos retirados do livro básico de Bioquímica, imagens do acervo didático da Histologia e textos básicos dessa disciplina, bem como tópicos do conteúdo programático de Odontologia Social e Biologia (principalmente artigos científicos da área).

Uma outra estratégia introduzida foi a realização de filmagens das aulas das matérias citadas, as quais posteriormente foram retransmitidas aos alunos. Com isso, foram realizadas discussões sobre o nível de profundidade e de confiança das anotações do caderno feitas pelos alunos, estimulando o aperfeiçoamento do registro das informações.

Além disso, desenvolveu-se a cultura geral voltada para a profissão, sendo transmitidas informações principalmente sobre a história da Odontologia.

Esses exercícios foram corrigidos e entregues aos alunos, sendo devidamente comentados em sala de aula. Ao mesmo tempo, serviram como fonte de dados da situação do graduando no tocante aos problemas lingüísticos existentes. Esses problemas foram anotados e analisados.

A partir dos exercícios realizados, e com base em FÁVERo (1998) e em PETRONI (2002), foi possível verificar os problemas lingüísticos relacionados a:

- leitura e interpretação de textos;

- nível de coesão e coerência textuais (tanto falado quanto escrito);

- nível ortográfico e gramatical;

- forma de registro das informações (anotações das aulas expositivas e práticas);

- capacidade de síntese.

O levantamento do desempenho nos exercícios foi realizado com base nas notas atribuídas $(0$ a $4-$ problemas graves; 5 a 7 - problemas aceitáveis; 8 a 10 - sem problemas). Esse levantamento reflete somente uma visão geral da situação dos ingressantes no curso de Odontologia da UBC, não retratando problemas individuais, os quais comporiam um grande leque de abordagem.

\section{RESULTADOS}

O Gráfico 1 contém a distribuição dos principais problemas em Língua Portuguesa nos ingressantes em Odontologia. A freqüência de deficiências concentra-se principalmente na produção de textos coerentes e coesos, bem como no registro das informações. Problemas graves ou ausência de problemas na leitura e interpretação de textos distribuem-se na mesma freqüência. Existe também uma alta freqüência de problemas ortográficos e gramaticais.

Alguns desses problemas podem ser observados nos exemplos abaixo, os quais ilustram alunos com problemas lingüísticos graves.

Exemplo 1: 


\begin{abstract}
"A guerra dos íons e moléculas
Existe um Rei chamado de Matéria viva, ele é muito poderoso porque ele tem um bilhões de soldado íons, eles querem acabar com as moléculas porque eles guardam o mapa que é o papel biológico. Eles invadiram o palácio das molécula e teve um grande confronto um dos soldados íons pegou o mapa, mas no confronto o mapa se rasgou-se e o soldado ficou com um pedaço.”
\end{abstract}

O exercício cujo resultado consta no exemplo 1 tinha por objetivo propor ao aluno a leitura de um texto introdutório em Bioquímica (retirado de referência básica da disciplina Bioquímica I do curso de Odontologia da UBC) e, posteriormente, a conversão do mesmo em um texto narrativo. O exemplo evidencia problemas graves de gramática, principalmente de pontuação e de concordância verbal e nominal, destacados pelos grifos. Observa-se, até certo ponto, uma tentativa de coesão textual.

Exemplo 2:

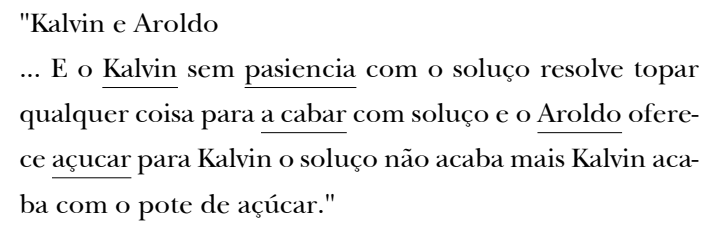

Nesse exemplo, o objetivo do exercício era criar um texto descritivo de uma charge de Calvin e Haroldo, personagens de "cartoons". Os alunos tinham acesso somente às figuras e aos textos presentes na charge. No trecho selecionado, são marcantes os problemas ortográficos (evidentes pelas palavras grifadas) e gramaticais, como pontuação, influenciando no nível coesivo do texto. Um detalhe marcante é a inconstância da aplicação de regras ortográficas, observada principalmente na grafia da palavra "açúcar" em contraste com "açucar". Vale ainda comentar que os nomes próprios "Calvin" e "Haroldo" estavam explícitos na charge com letras grandes e em negrito, e mesmo assim o aluno escreveu esses nomes erroneamente.

Exemplo 3:

"Título: A cárie

A carie dentaria, nos locais de menor infra estrutura, está autíssima a taxa de pessoas com problemas dentarios. Esse é um problema nacional, pois envolve todos os segmentos da sociedade, em especial os mais carentes. Que não tem uma condição melhor de saúde, falta de higiene é um dos pontos em primeiro na infância. Por causa dessa carência de água fluoretada, os índices CPOD nas crianças são bastantes altos nessas comunidades mais pobres."

O exercício do exemplo 3 tinha por objetivo treinar coesão e coerência textuais. As frases não-grifadas constantes no exemplo estavam explícitas no exercício, o qual solicitava que o aluno as completasse de forma a tornar coesa uma idéia. As frases grifadas foram introduzidas pelos alunos e denotam graves problemas de coesão e coerência textuais. Em nenhum momento são utilizados conectivos ou repetição de palavras-chave que pudessem sinalizar uma tentativa de coesão.

\section{DISCUSSÃO}

As diretrizes curriculares propostas para o curso de Odontologia pelo Conselho Nacional (MINISTÉRIO DA EDUCAÇÃO E CULTURA, 2002) deixam claras, no $4^{\circ}$ artigo, parágrafo III, as metas em comunicação que um cirurgião-dentista formado deve atingir: "A comunicação envolve comunicação verbal, não-verbal e habilidades de escrita e leitura”.

A introdução da disciplina de Língua Portuguesa no currículo de Odontologia justifica-se mediante essas metas traçadas pelo Conselho Nacional. Ao mesmo tempo, as características dessa demanda delineadas pelo governo federal traduzem uma necessidade universal de qualquer profissional de nível superior, e não são exclusivas da profissão odontológica. Diante disso, uma disciplina que tratasse da língua portuguesa por si só seria suficiente para dar respaldo curricular a essa exigência. Não seria necessária uma adequação, à primeira vista, às necessidades do curso de Odontologia.

A disciplina de Língua Portuguesa da Universidade Braz Cubas possuía essas características: o mesmo conteúdo programático era ministrado para todos os cursos da Universidade, na tentativa de fornecer maior liberdade aos alunos no tocante a matrículas e a distribuição de créditos, uma vez que o aluno poderia fazer essa disciplina em qualquer curso.

No curso de Odontologia, essa sistemática acabou sendo ineficaz, decorrente sobretudo das necessidades dos alunos ingressantes. $\mathrm{O}$ desinteresse pela disciplina e a ausência de contexto curricular que suportasse seus objetivos específicos levou os alunos a desacreditarem na necessidade da mesma em sua formação profissional. Diante disso, no primeiro semestre de 2002, foi realizada uma adaptação da disciplina de Língua Portuguesa ao contexto curricular do curso de Odontologia da Universidade Braz Cubas, com o intuito de torná-la mais útil aos alunos e, 
ao mesmo tempo, mais interdisciplinar. Com essas modificações, foi possível detectar os reais problemas lingüísticos dos ingressantes no curso de Odontologia, direcionando a disciplina de Língua Portuguesa a esses problemas.

Os objetivos da disciplina de Língua Portuguesa da UBC são:

- Permitir que o aluno possa desenvolver um raciocínio analítico, que o ajude na análise e na construção das diferentes estruturas textuais.

- Criar situações que estimulem o aluno a apreciar a leitura e que auxiliem no desenvolvimento da interpretação textual.

- Apresentar ao aluno textos em atualidades gerais e de conhecimento específico da área da Saúde, que estimulem a discussão e a organização de idéias.

- Promover situações que auxiliem o aluno na organização do seu estudo.

As estratégias até então adotadas para se atingirem esses objetivos eram baseadas em aulas expositivas, cujo guia de estudo estava apostilado. Os temas tratados em cada aula não eram específicos da área de Odontologia, sendo de caráter geral. Todo o material estava voltado para a leitura e interpretação de textos científicos, principalmente da área de $\mathrm{Hu}$ manas.

As modificações incluídas restringiram-se à criação de novo material didático, contendo textos específicos das matérias do primeiro semestre. Com isso, os alunos conseguiram compreender a importância da Língua Portuguesa em seus currículos, uma vez que esta dedicou-se integralmente a introduzir as ferramentas necessárias à interpretação desses textos científicos voltados ao contexto curricular vivenciado pelo estudante. Nesse sentido, são trabalhadas principalmente as partes constituintes de um texto científico na área odontológica, o qual está estruturado basicamente em conceitos, definições, classificações e descrições. Os alunos passaram então a ser treinados a identificar essas partes no texto, bem como a reproduzi-las com suas palavras sob a forma de resumos. Ao mesmo tempo, alguns outros exercícios foram aplicados, voltados principalmente ao diagnóstico dos problemas lingüísticos, cujos exemplos foram citados neste trabalho.

O Gráfico 1 confirma as deficiências lingüísticas dos alunos ingressantes na UBC. Esse quadro pode ser extrapolado para outros grupos de alunos das escolas privadas, guardadas as devidas proporções e particularidades inerentes a cada público. De qualquer maneira, até certo ponto essa situação é conhecida por todo docente que trabalha com o ensino superior, principalmente privado. $\mathrm{O}$ que falta aos docentes é um diagnóstico mais acurado e técnico dessas deficiências, fato que a disciplina de Língua Portuguesa pode suprir, uma vez fazendo parte do currículo de Odontologia.

Realizado o diagnóstico da situação lingüística do corpo discente, o segundo obstáculo é criar estratégias para suprir essas deficiências. Um fato merece atenção nessa reflexão: uma instituição de ensino superior, ao matricular um aluno com o quadro lingüístico descrito, assume como seu o problema do seu cliente. Diante disso, essa instituição deve oferecer ferramentas e oportunidades ao aluno para que
Gráfico 1 - Distribuição dos problemas lingüísticos apresentados pelos alunos ingressantes na Universidade Braz Cubas no ano de 2002. Os problemas apresentam-se categorizados segundo alguns tópicos fundamentais diretamente relacionados a leitura e escrita de textos.

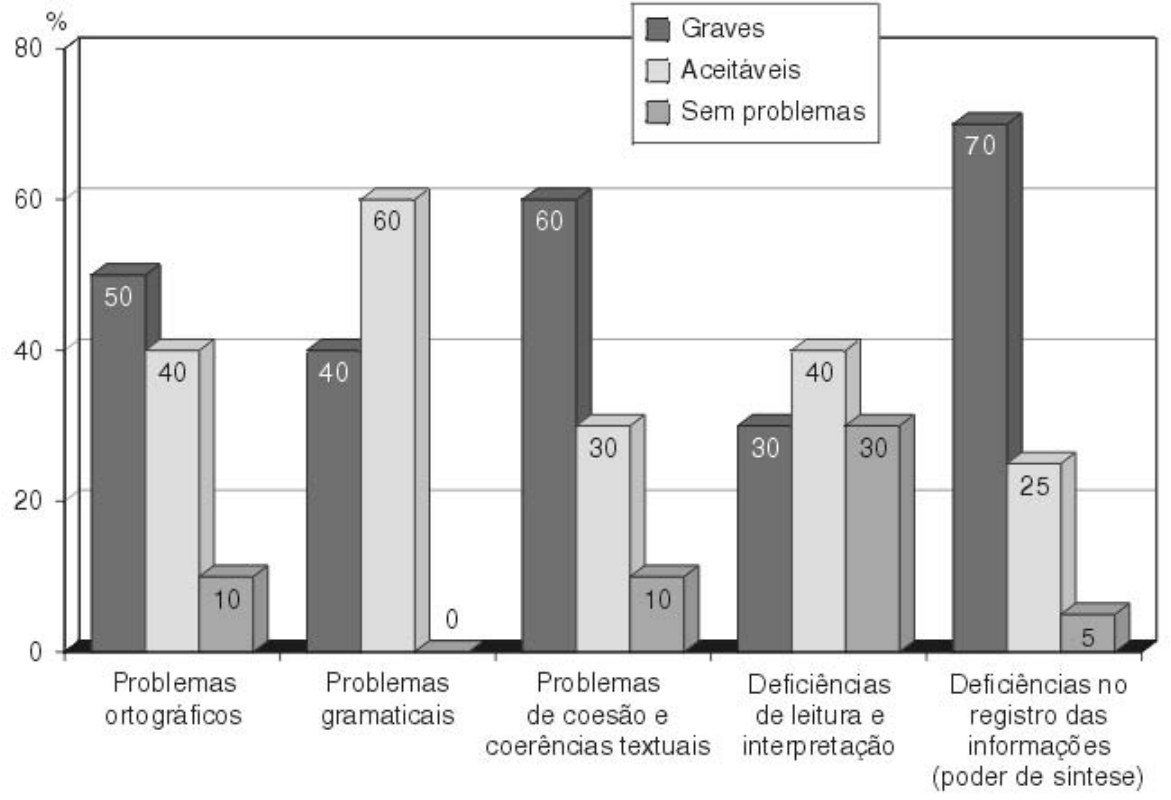


ele se conscientize de suas deficiências e, ao mesmo tempo, seja orientado a enfrentá-las. Atualmente algumas escolas têm optado por seguir esse caminho criando oficinas de leitura e interpretação de textos, as quais ficam disponíveis ao estudante durante todo o seu curso (SOUZA, 2003). Os resultados nessas instituições têm sido detectados satisfatoriamente a partir de desempenhos no Provão. São medidas concretas e bastante eficientes, tanto do ponto de vista curricular quanto operacional e pedagógico, já que funcionam sob o regime de tutoria e não se restringem somente a um semestre.

Vale dizer que a modificação de um estado lingüístico não se faz em um semestre, carga horária média das disciplinas de Língua Portuguesa nos currículos de Odontologia. É necessário maior investimento de tempo, mas também não tanto assim. Acreditamos, a partir de nossa experiência (CORRÊA; NOVELLI, 1998), que em dois anos alunos com deficiências graves, como as demonstradas nos exemplos, adquirem habilidades de escrita e leitura suficientes para cursar, de maneira satisfatória, o curso de Odontologia. O trabalho nesse sentido, a nosso ver, deve ser necessariamente interdisciplinar (FAZENDA, 2000), sendo treinadas habilidades lingüísticas a partir de materiais didáticos vinculados às disciplinas obrigatórias da Odontologia. Experienciamos essa estratégia e notamos que, pelo intercâmbio da Língua Portuguesa com os docentes das demais disciplinas da Odontologia, foi possível compartilhar com esses professores os problemas levantados, instigando os mesmos a darem continuidade, em suas aulas, aos princípios lingüísticos trabalhados em Língua Portuguesa. Não se trata de ensinar Português na matéria de Endodontia ou Dentística, mas sim de aplicar os princípios de verificação textual de forma direcionada a partir do conteúdo específico da matéria. Um professor de Português conversando com um professor de Dentística podem, em algum momento, em nome do aprendizado do aluno, falar a mesma língua.

\section{CONClusões}

A disciplina de Língua Portuguesa é importante para sinalizar às demais disciplinas os problemas lingüísticos enfrentados pelo aluno ingressante. Com isso, os demais docentes entram em contato com dados reais acerca da situação do aluno no tocante às dificuldades de leitura, interpretação e raciocínio lógico.

A presença dessa disciplina no currículo odontológico deve estar necessariamente baseada na inter- disciplinaridade em todos os seus níveis, e não só em âmbito do material didático.

Somente um semestre é completamente insuficiente para promover qualquer mudança no status quo lingüístico do aluno. A continuidade dos esforços iniciados na disciplina de Língua Portuguesa deve abranger as demais disciplinas do primeiro e segundo semestres do curso de Odontologia.

\section{ABSTRACT}

The discipline of Portuguese - its importance in the dental curriculum

The discipline of Portuguese is part of the mandatory dental curriculum at Braz Cubas University (BCU), Mogi das Cruzes, Brazil. In all BCU courses the discipline of Portuguese is focused on the development of the pupil's reading and writing skills. Textual cohesion and logic are emphasized, as well as topics on grammar and orthography. In February 2002, adaptations in the discipline of Portuguese were made through the introduction of didactic materials and strategies based on an interdisciplinary approach. Before these adaptations could be carried out, a linguistic diagnosis of the students was made in order to evaluate their trends of textual production. This paper focuses on the methodological principles of the performed linguistic diagnosis and discusses the students' linguistic short-comings. A discussion about the modifications introduced in the discipline of Portuguese and their consequences to the BCU dental curriculum is also carried out.

\section{DESCRIPTORS} lum.

Teaching, trends. Education, dental. Curricu-

\section{REFERÊNCIAS BIBLIOGRÁFICAS}

CORRÊA, L., NOVELLI, M. D. Avaliação dos conhecimentos sobre Patologia Geral dos alunos de graduação utilizando diferentes formas de linguagem. RPG Rev Pós Grad, v. 5, n. 4, p. 244, out./dez., 1998. [resumo n. 1]

FÁVERO, L. L. Coesão e coerência textuais. São Paulo : Ática, 1998.

FAZENDA, I. Didática e interdisciplinaridade. 3. ed. Campinas : Papirus, 2000.

FERNANDEZ, S. A. F. Ensino superior privado no Brasil: a óptica discente. São Paulo, 1993. 273 p. Tese (Doutoramento em Filosofia da Educação) - Faculdade de Educação, Universidade de São Paulo.

MINISTÉRIO DA EDUCAÇÃO E CULTURA. Diretrizes curriculares nacionais do curso de Graduação em Odontologia. Resolução CNE/CES 3, de 19 de fevereiro de 2002. São Paulo : MEC, 
2002. Http://www.mec.gov.br/sesu/ftp/resolucao/ 0302Odontologia.doc. Acesso em: 04/04/2003.

PETRONI, M. R. Produção do texto argumentativo escrito: aspectos linguísticos e discursivos. São Paulo, 2002. 317 p. Tese (Doutora- do) - Faculdade de Filosofia, Letras e Ciências Humanas da Universidade de São Paulo.

SOUZA, M. M. Quando a universidade tenta corrigir o português. O Estado de S. Paulo, 23 de março de 2003. 